\title{
Incomplete pentalogy of Cantrell: a case report
}

\author{
Heera T. Shenoy ${ }^{1}$, Prasanna Venugopal ${ }^{1}$, Raghu S. ${ }^{2}$, Remash K. ${ }^{3 *}$
}

${ }^{1}$ Department of Obstetrics and Gynecology, ${ }^{2}$ Department of Radiodiagnosis, ${ }^{3}$ Department of Cardiology, Travancore Medical College, Kollam, Kerala, India

Received: 18 November 2018

Accepted: 13 December 2018

\section{*Correspondence:}

Dr. Remash K.,

E-mail: heerarprabhu@gmail.com

Copyright: $\odot$ the author(s), publisher and licensee Medip Academy. This is an open-access article distributed under the terms of the Creative Commons Attribution Non-Commercial License, which permits unrestricted non-commercial use, distribution, and reproduction in any medium, provided the original work is properly cited.

\begin{abstract}
Pentalogy of Cantrell (PC) is a rare congenital anomaly characterized by a defect in the lower sternum, anterior diaphragm, and anterior abdominal wall; ectopia cordis; and congenital heart disease. Authors report a case of male foetus terminated at 20 weeks of gestation with an Incomplete (class 3) pentalogy of Cantrell presenting with gastroschisis, ectopia cordis and absence of lower sterna. Prognosis of pentalogy of Cantrell depends on severity of intra and extra cardiac defects, pulmonary hypoplasia, extent of abdominal wall defect, cerebral anomalies and diaphragmatic herniation. Full pentalogy of Cantrell is a severe and rare syndrome, but incomplete forms with combination of two or three defects are reported frequently similar to present case report. Early diagnosis through obstetric ultrasound would help in improved informed clinical decision making on the part of the obstetrician and family.
\end{abstract}

Keywords: Abdominal wall defect, Congenital, Ectopia cordis, Gastroschisis, Incomplete, Pentalogy of Cantrell (PC)

\section{INTRODUCTION}

Cantrell first described the full spectrum of PC. ${ }^{1}$ The Pentalogy of Cantrell, PC is an extremely rare and usually lethal anomaly. The full spectrum consists of five anomalies: A deficiency of the anterior diaphragm, a midline supraumbilical abdominal wall defect, a defect in the diaphragmatic pericardium, ectopia cordis various congenital intracardiac abnormalities, and a defect of the lower sternum. ${ }^{1}$ Authors report a case of incomplete Pentalogy of Cantrell. Most cases are diagnosed early in the second trimester, when ectopia cordis associated with gastroschisis or omphalocele is observed. ${ }^{2}$ The first description of PC was made by Cantrell et al in 1958, who reported 5 cases with this anomaly. ${ }^{1} \mathrm{Up}$ to now, there are some case reports that have been classified as full spectrum, which have all of the five defects and incomplete forms with lesser defects of the pentalogy of Cantrell. An associated intracardiac anomaly is the rule, such as septal defects, Ebstein's anomaly, Fallot's tetralogy or single atrium. In $75 \%$ of the cases pericardium may be absent.

\section{CASE REPORT}

A 27-year-old G2 IUD1, booked case on regular antenatal care at Travancore Medical College hospital had dating scan corresponding to POG and low risk NT scan. Her medical history w unremarkable. Parents were non-consanguineous on routine anomaly scan at 20 weeks gestation, foetus in breech presentation with growth corresponding to POG showed a large abdominal wall and partially chest wall defect through which abdominal organs and cardia protruded out with no membranous covering with a diagnosis of gastroschisis.

There was spinal deformity (kyphoscoliosis) with pelvic deformity and rotation of lower limbs.4 D Ultrasonogram and MRI confirmed the above findings. No cardiac malformation was noted (Figure 1 and 2). 


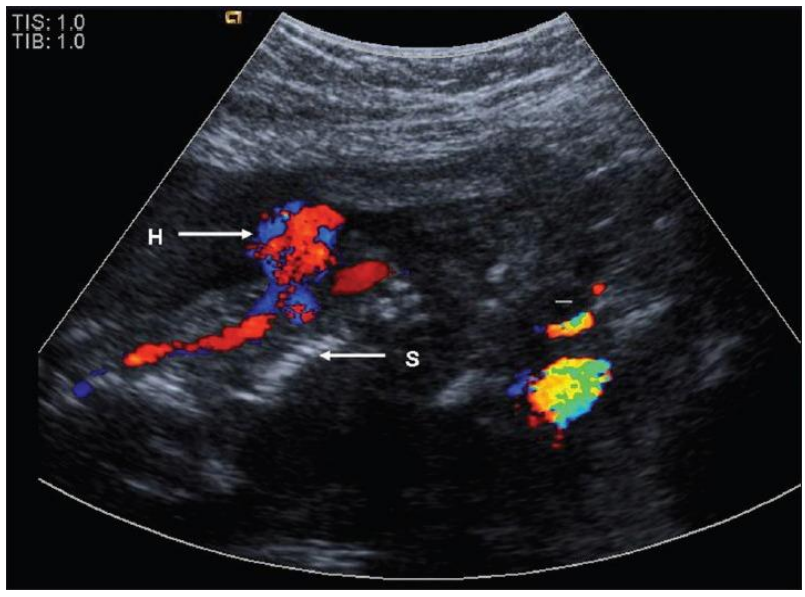

H-heart, S-spine.

Figure 1: Fetal ultrasound scan showing the ectopia cordis.

The parents were counselled regarding prognosis of the foetus and offered termination of pregnancy. With informed consent, oral mifepristone $200 \mathrm{mg}$ followed by one dose of $400 \mu \mathrm{g}$ vaginal misoprostol was given.
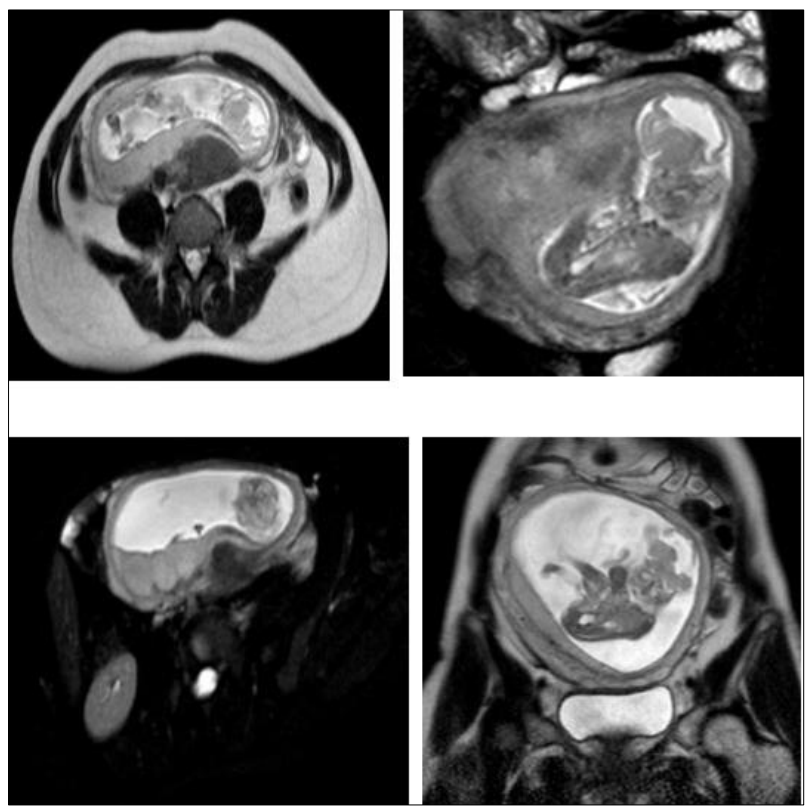

Figure 2: MRI showing features suggestive of gastroschisis, ectopia cordis.

She expelled a foetus weighing 200grams showing ectopia cordis, lower sternal defect, large supraumbilical anterior abdominal wall defect with liver, spleen and loops of small intestine and colon with tinea protruding outside characteristic of incomplete PC along with kyphoscoliosis spinal deformity and club foot (Figure 3 and 4). The thoraco-abdominal wall defect was extending from the umbilicus to the upper third of the body of the sternum. The liver was enlarged with a prominent caudate lobe.

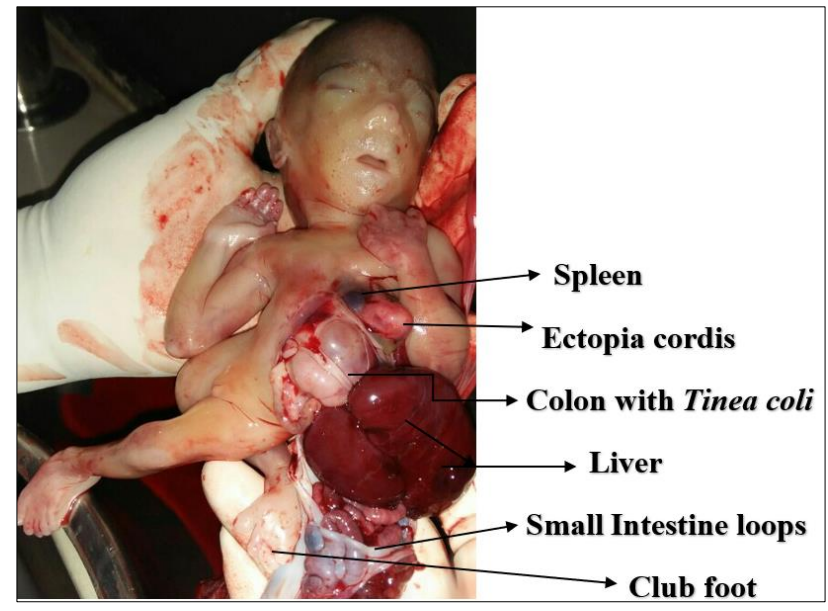

Figure 3: The baby at 20 weeks with the incomplete pentalogy of Cantrell having lower sternal defect with thoracoabdominal ectopia cordis, entire liver, spleen, gastroschisis with intestinal loops (both small and large) and kyphoscoliosis with pelvic deformity with rotation of lower limb and club foot.

Consent for autopsy was denied by the parents and hence not done. The external genitalia showed a normal male phenotype.

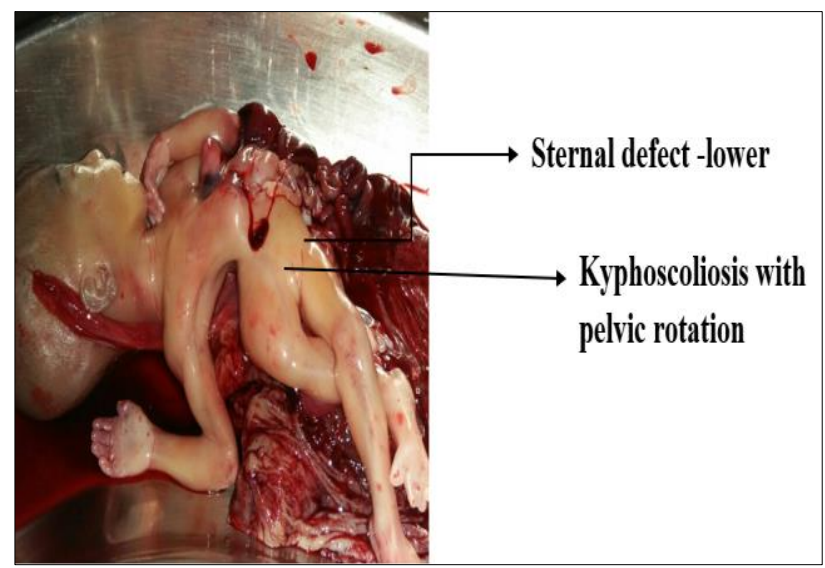

Figure 4: The baby at 20 weeks with the incomplete pentalogy of Cantrell having kyphoscoliosis with pelvic deformity and rotation of lower limb; club foot is also noted.

\section{DISCUSSION}

Cantrell's pentalogy consists of: midline supra-umbilical abdominal wall defect, defect of the lower sternum, deficiency of the anterior diaphragm, defect in diaphragmatic pericardium, congenital intracardiac defects.

\section{Classification}

Toyama suggested the following classification for Pentalogy of Cantrell ${ }^{3}$ : 
- Class I: definite diagnosis with five defects present.

- Class II: probable diagnosis with four defects (includes intracardiac and abdominal wall defects).

- Class III: incomplete expression with combination of defects (but with the presence of sternal abnormality).

Present case fits into Class III PC with midline supraumbilical abdominal wall effect, defect of lower sternum and thoracoabdominal ectopia cordis.

\section{Embryology}

According to Cantrell et al, PC is due to failure of development of ventral mesoderm at about 14 to 18 days of embryonic life Complete or incomplete failure of midline fusion results in a range of related malformations from isolated ectopia cordis to complete ventral evisceration.

On the basis of embryonic development this syndrome may be classified into two groups ${ }^{4}$ :

- Due to mesodermal defect which includes defects in diaphragm, pericardium and intracardiac lesions.

- Due to failure of migration of paired structures which includes sterna and abdominal wall defects.

Because of various phenotypes of abdominal wall defect in Pentalogy of Cantrell, multiple factors are said to be responsible, including mechanical teratogens, major gene mutations, chromosomal abnormalities such as trisomy 13 and trisomy 18 and disrupted vessels defects. Mutations of TAS gene which mapped at Xq25-q26.1 area, is mentioned to have a role in fusion of sternum, multiple cardiac, diaphragmatic, anterior abdominal defects and additional abnormalities. ${ }^{5}$ Perixoto and Filho et al, mentioned club foot in few cases. Authors also had club foot in present foetus. ${ }^{6}$

\section{Incidence}

Complete pentalogy of Cantrell (PC) is a rare condition with an incidence of 1 in 100000 pregnancies. $^{1}$ : PC1 consists of: Ectopia cordis and intracardiac anomalies, lower sternal defect, midline supraumbilical thoracoabdominal wall defect, anterior diaphragmatic defect, defect of diaphragmatic part of pericardium that results in relation between pericardial cavity and peritoneum.

Most cases are sporadic, and no recurrences have been reported. There is male dominance with a male to female ratio of 2.7:1 as in ours. An incidence of ectopia cordis was reported to be 5.5 to 7.9 per 1 million live births by Chandran S. et al, Alphonso $\mathrm{N}$ et al. cited the same incidence but limited it to thoracic ectopia cordis. ${ }^{2,7}$

Ectopia cordis occurs when the heart is displaced outside the chest wall. ${ }^{8}$ The displacement of the heart can be cervical, cervico-thoracic, thoracic, thoraco-abdominal, or abdominal. The most common types are thoracoabdominal and abdominal an associated intracardiac 1 anomaly is the rule, such as septal defects, (VSD) in $100 \%$ of cases, ASD in $50 \%$ of cases, Ebstein's anomaly, Fallot's tetralogy in $33 \%$ of cases or ventricular diverticulum in $20 \%$ of PC. In $75 \%$ of the cases pericardium may be absent. Extracardiac abnormalities. ${ }^{9}$ in PC include craniofacial anomalies such as cleft lip and/or palate; central nervous system. ${ }^{10}$ anomalies such as hydrocephalus; skeletal malformations such as clubfoot, absence of tibia or radius and abdominal abnormalities such as polysplenia and gallbladder agenesis. sternal fusion defect is a rare malformation and an inferior type is seen in pentalogy of Cantrell. Sternal defects include bifid sternum (26\%), absent xiphoid $(10 \%)$ and absent lower $2 / 3$ of sternum $(9 \%)$. Anterior abdominal wall defect is mostly an omphalocele (63\%). ${ }^{11}$ A ventral retrosternal defect of the diaphragm occurs in $91 \%$ of the cases. Omphalocele, cardiac septal defects, absent pericardium, cleft lip and defects in the sternum and diaphragm were noted in the reported case as well.

\section{Diagnosis/imaging studies}

Pentalogy of Cantrell can be suspected by antenatal ultrasound. It has been suggested that magnetic resonance imaging and prenatal fetal echocardiography provide optimal assessment of fetuses with PC. Using 2D ultrasound in the first trimester, and the adjunctive use of the 3D ultrasound may help to enhance the visualization of the fetal anomalies in different orthogonal planes, even in unfavorable fetal positions. Intrauterine diagnosis of abdominal wall defects before 12 weeks is not possible as herniation of bowel out of abdomen is a normal event in foetal development at that time. After 12 weeks, the differential diagnoses include omphalocele, pentalogy of Cantrell and gastroschisis. ${ }^{12}$ If diagnosis is made by ultrasound, screening for chromosomal abnormalities is recommended. Following prenatal diagnosis, termination may be offered in severe cases especially with abnormal karyotype.

\section{Prognosis}

Ghidini et al, in his analysis on ten cases of complete PC which were diagnosed antenatally by ultrasound observed poor prognosis. ${ }^{13}$ Omphalocele, cardiac septal defects, absent pericardium, cleft lip and defects in the sternum and diaphragm were noted in the reported case as well Prognosis of pentalogy of Cantrell depends on severity of intra and extra cardiac defects, pulmonary hypoplasia, extent of abdominal wall defect, cerebral anomalies and diaphragmatic herniation.

\section{Treatment}

The treatment strategy and prognosis depend on the size of the abdominal wall defect, the type of EC, and the associated anomalies. A multidisciplinary team should follow-up milder forms in order to determine the best 
time for delivery. After delivery, repair of the omphalocele should not be delayed. Repair of the sternal, diaphragmatic, and pericardial defects can be attempted at the same time. ${ }^{14}$ Surgical correction is often difficult due to the hypoplasia of the thoraco-abdominal cavity and also inability to enclose the ectopic heart The mean survival rate without any interventional surgery is about 36 hours. $^{15}$ Studies showed that even with care monitoring in professional centers and multiple corrective surgeries, they had high morbidity and mortality rate and long-time prognosis is poor. ${ }^{16}$ The limitations in some of them could be financial support and technical expertise to deal with. ${ }^{17}$

\section{CONCLUSION}

Diagnosis of pentalogy of Cantrell cannot be made unless radiologists look into when multiple congenital anomalies are diagnosed during fatal morphology ultrasonogram. Awareness regarding this rare diagnosis among obstetricians is a must and parents should be appropriately counselled regarding the prognosis before decision about termination of pregnancy in previable foetuses.

Funding: No funding sources

Conflict of interest: None declared

Ethical approval: Not required

\section{REFERENCES}

1. Cantrell JR, Haller JA, Ravitch MM. A syndrome of congenital defects involving the abdominal wall, sternum, diaphragm, pericardium, and heart. Surg Gynecol Obstet. 1958;107(5):602-14.

2. Suresh Chandran DA. Pentalogy of Cantrell: an extremely rare congenital anomaly. J Clinic Neonatol. 2013;2(2):95.

3. Toyama WM. Combined congenital defects of the anterior abdominal wall, sternum, diaphragm, pericardium, and heart: a case report and review of the syndrome. Pediatr. 1972;50(5):778-92.

4. Daltro P, Fricke BL, Kline-Fath BM, Werner H, Rodrigues L, Fazecas T, et al. Prenatal MRI of congenital abdominal and chest wall defects. Am J Roentgenol. 2005;184(3):1010-6.

5. Taksande AM, Vilhekar KY. A case report of ectopia cordis and omphalocele. Indian $\mathrm{J}$ Hum Genetics. 2013;19(4):491.

6. Peixoto-Filho FM, Carneiro do Cima L, NakamuraPereira M. Prenatal diagnosis of Pentalogy of
Cantrell in the first trimester: Is 3-dimensional sonography needed?. J Clinic Ultrasound. 2009;37(2):112-4.

7. Alphonso N, Venugopal PS, Deshpande R, Anderson D. Complete thoracic ectopia cordis. Europ J Cardiothoracic Surg. 2003;23(3):426-8.

8. Kumar B, Sharma C, Sinha DD. Ectopia cordis associated with Cantrell's pentalogy. Ann Thorac Med. 2008;3(4):152.

9. Sowande OA, Anyanwu LJ, Talabi AO, Babalola OR, Adejuyigbe O. Pentalogy of Cantrell: a report of three cases. J Surgic Technique Case Report. 2010;2(1):20

10. Ranganath P, Pradhan M. Complete pentalogy of Cantrell with craniorachischisis: a case report. J Prenatal Med. 2012;6(1):10.

11. Chen CP. Syndromes and disorders associated with omphalocele (II): OEIS complex and Pentalogy of Cantrell. Taiwanese J Obstet Gynecol. 2007;46(2):103-10.

12. Jafarian AH, Omidi AA, Fazel A, Sadeghian H, Joushan B. Pentalogy of Cantrell: a case report. Journal of research in medical sciences: the official $\mathbf{J}$ Isfahan Univers Med Scienc. 2011;16(1):105.

13. Ghidini A, Sirtori M, Romero R, Hobbins JC. Prenatal diagnosis of pentalogy of Cantrell. J Ultrasound Med. 1988;7(10):567-72.

14. Balderrábano-Saucedo N, Vizcaíno-Alarcón A, Sandoval-Serrano E, Segura-Stanford B, ArévaloSalas LA, de la Cruz LR, et al. Pentalogy of Cantrell: forty-two years of experience in the Hospital Child of Mexico Federico Gomez. World J Ped Congenital Heart Surg. 2011;2(2):211-8.

15. Forzano F, Daubeney PE, White SM. Midline raphe, sternal cleft, and other midline abnormalities: a new dominant syndrome?. Am J Med Genetics Part A. 2005;135(1):9-12.

16. O'Gorman CS, Tortoriello TA, McMahon CJ. Outcome of children with pentalogy of Cantrell following cardiac surgery. Ped Cardiol. 2009;30(4):426-30.

17. Khanna PC, Bharati A, Merchant SA. Pentalogy of Cantrell or one of its variants. Appl Radiol. 2005;34(10):40-3.

Cite this article as: Shenoy HT, Venugopal $\mathrm{P}$, Raghu S, Remash K. Incomplete pentalogy of Cantrell: a case report. Int J Reprod Contracept Obstet Gynecol 2019;8:325-8. 